\title{
Prevalence of Smoking among Medical Students in a Tertiary Care Teaching Hospital
}

\author{
Neharika Shrestha, ${ }^{1}$ Nikhil Shrestha, ${ }^{1}$ Suzit Bhusal, ${ }^{2}$ Asmita Neupane, ${ }^{2}$ Rakshya Pandey, ${ }^{2}$ Nita Lohala, ${ }^{3}$ Arpan \\ Pratik Bhandari, ${ }^{4}$ Mandeep Kumar Yadav, ${ }^{5}$ Abhinav Vaidya ${ }^{6}$ \\ 'Oxford University Clinical Research Unit-Nepal, Patan Academy of Health Sciences, Lalitpur, Nepal, ${ }^{2}$ Kathmandu \\ Medical College and Teaching Hospital, Kathmandu, Nepal, ${ }^{3}$ Kathmandu University School of Medical Sciences, \\ Dhulikhel, Nepal, ${ }^{4 B} \& B$ Hospital, Lalitpur, Nepal, ${ }^{5}$ yoti Hospital, Kathmandu, Nepal, ${ }^{6}$ Department of Community \\ Medicine, Kathmandu Medical College and Teaching Hospital, Kathmandu, Nepal.
}

\section{ABSTRACT}

Introduction: Tobacco smoking is one of the most important preventable risk factors for noncommunicable diseases. It has been seen that medical students have a higher frequency of smoking compared to the general population. This study aims to determine the prevalence of smoking among third-year medical students in a tertiary care teaching hospital in Nepal.

Methods: This descriptive cross-sectional study was conducted among the hospital's third-year undergraduate medical students over a four-month period (October 2019 to January 2020). Ethical clearance was received from the Institutional Review Committee of Kathmandu Medical College and Teaching Hospital. The whole sampling technique was used to collect data. The Global Health Professional Students Survey questionnaire was used to collect data. Data analysis was done in the statistical package for social sciences.

Results: The prevalence of current smoking among selected medical students of Kathmandu Medical College and Teaching Hospital is 34 (30.1\%), majority male 26 (23\%). Fifty-six (49.4\%) of them had ever smoked cigarettes in their life, and $27(23.9 \%)$ had their first cigarette in late adolescence. The number of students who used other forms of tobacco was comparatively lower i.e. 6 (5.3\%). Many of the students $53(46.9 \%)$ were exposed to second-hand smoke both at home and in public, while 18 (15.9) exposed only at public places, and 6 (5.3\%) only at home.

Conclusions: Our study has concluded that there is a notable prevalence of smoking among the participants. This points to the need for specific training sessions in their clinical years about smoking cessation for themselves and regarding counseling for patients.

Keywords: medical student; prevalence; smoking; tobacco.

\section{INTRODUCTION}

Tobacco is attributed to be a significant cause of preventable chronic diseases, and a major risk factor for premature death. ${ }^{1}$ WHO states that 7 million deaths occur annually due to tobacco use, which is expected to rise to 8 million by the end of $2030 .{ }^{2}$ Currently, $80 \%$ of the 1 billion smokers worldwide are from developing countries. ${ }^{3,4,5}$ Health professionals play a crucial role in the prevention and cessation of tobacco use via techniques such as counseling..$^{6,7}$

Correspondence: Dr. Neharika Shrestha, Oxford University Clinical Research Unit-Nepal, Patan Academy of Health Sciences, Lalitpur, Nepal. Email: sthaneharika5@gmail.com, Phone: +9779849983080. 
Providing cessation training to health professional students is a vital towards tobacco control, which will aid WHO's Tobacco Control programs. ${ }^{8}$

But most health professional students in Afro-Asian developing countries have little-to-no training on tobacco cessation techniques. ${ }^{9}$ Providing these trainings can have a positive impact on the future professional practice strengthening tobacco control. Although health professionals who themselves smoke, cannot be expected to persuade a patient to quit smoking. ${ }^{10,11}$

This study aims to estimate the prevalence of smoking and tobacco products used by third-year medical students and their attitudes and behaviour towards it and smoking cessation trainings.

\section{METHODS}

This descriptive cross-sectional study was conducted among all third-year undergraduates of Kathmandu Medical College and Teaching Hospital after taking the ethical clearance from the Institutional ethical review Committee, over four months in October 2019 to January 2020.

All the third-year medical students enrolled currently in the medicine in the tertiary teaching hospital who gave consent were included in the study. Chronically absent students, those students who were seriously ill at the time of the study, also students other than those in the third year were not included in the study. Students were informed about the study and those willing to participate were given consent paper for signature. A self-administered validated Global Health Professional Students Survey (GHPSS) questionnaire, was used in this study, developed by the World Health Organization (WHO), the United States Centers for Disease Control and Prevention (CDC) and the Canadian Public Health Association. ${ }^{12,13}$

Current smokers were defined as someone who smokes any tobacco product, either daily occasionally, during the past 30 days according to the WHO definition of a "smoker". Ever-smoker was defined as one who had ever once smoked in his lifetime. Other tobacco products were defined as chewing tobacco, snuff, bidis, hookah, cigar, or pipes. Non-smokers were defined as those who never smoked a cigarette in their lifetime. ${ }^{14}$

The WHO's GHPSS Questionnaire is a validated tool for screening smoking among university students as stated by the paper published by Gualano MR, et al. ${ }^{12}$ The questionnaire was administered during regular class sessions in an anonymous, voluntary manner, according to the protocol. The questionnaire was distributed to the participants by a single investigator and the questionnaire was collected on the same day. Participants were informed about the anonymity of their personal information, as well as of their right to opt-out of the study, any time within the study period. Despite the whole sampling, the following bias could occur such as information bias, reporting bias, social desirability bias, and non-response bias. Such bias present in the study were minimized as possible.

Data collected was thoroughly checked for its completeness. Only those forms, which have complete data were included in the study. The data was then coded and double-entry done in the statistical package for the social sciences (SPSS) version 23.0. The data was processed and analyzed by using simple descriptive statistics; in terms of percentage and frequency.

\section{RESULTS}

The period prevalence of current smokers among thirdyear medical students of Kathmandu Medical College Teaching Hospital is $34(30.1 \%)$. In the study we achieved a very good total response rate of $98 \%$. Among the 113 participants, 56 (49.4\%) were ever smokers and a major proportion of the students, 27 (23.9\%) were first introduced to tobacco smoking in their late adolescent years (i.e. 20-24 years of age). The number of students using other forms of tobacco products such as chewing tobacco, snuff, bidis, hookah, cigar or pipes was proportionately lower that those smoking tobacco, i.e. $6(5.3 \%)$ and $14(12.4 \%)$ of the students had ever used the other forms of tobacco products (Figure 1).

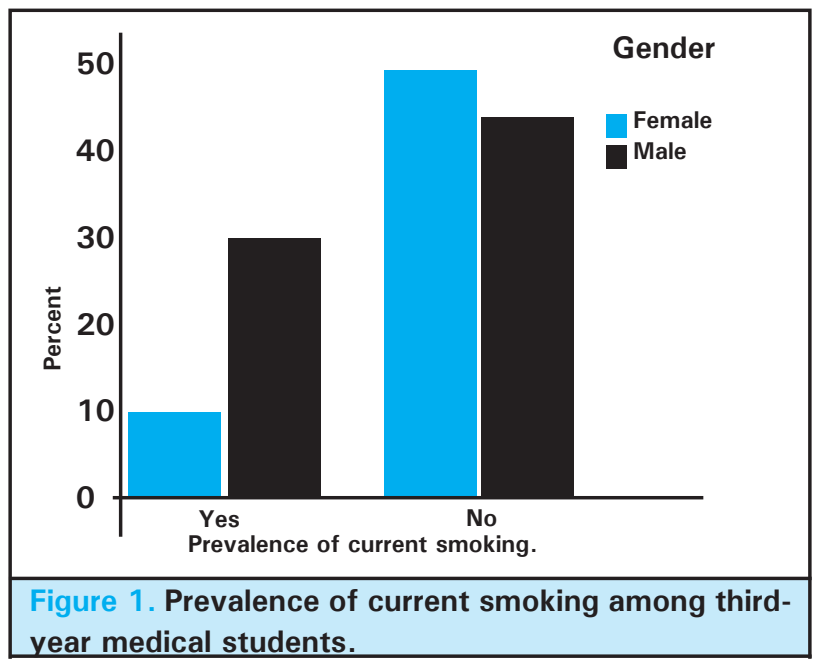

In this study we found that the majority of current smokers $26(23 \% \mathrm{w})$ were male, while only a small percent of the smokers were females $8(7.1 \%)$. And most of the current smokers $25(22.1 \%)$ were of the 
age group of $19-24$ years, with few smokers $8(7.1 \%)$ also of age group of 25-29 years.

Non-smokers were more accepting of placing a ban on tobacco compared to smokers; whether it be banning sale to adolescents 69 (87.3\%) versus (vs.) 26 (76.5\%), banning tobacco advertisement 61 (77.2\%) vs. 20 $(58.8 \%)$, banning smoking in restaurants 62 (78.5\%) vs. $15(44.1 \%)$, banning smoking in disco/bars/pubs $43(54.4 \%)$ vs. $10(29.4 \%)$ or banning smoking in enclosed public places $70(88.6 \%)$ vs. $25(73.5 \%)$. Among the participants the prevalence of exposure to environmental tobacco smoke at both home and public places was 53 (46.9\%), exposure at home only was $6(5.3 \%)$ and exposure at only public places was 18 (15.9\%) (Figure 2).

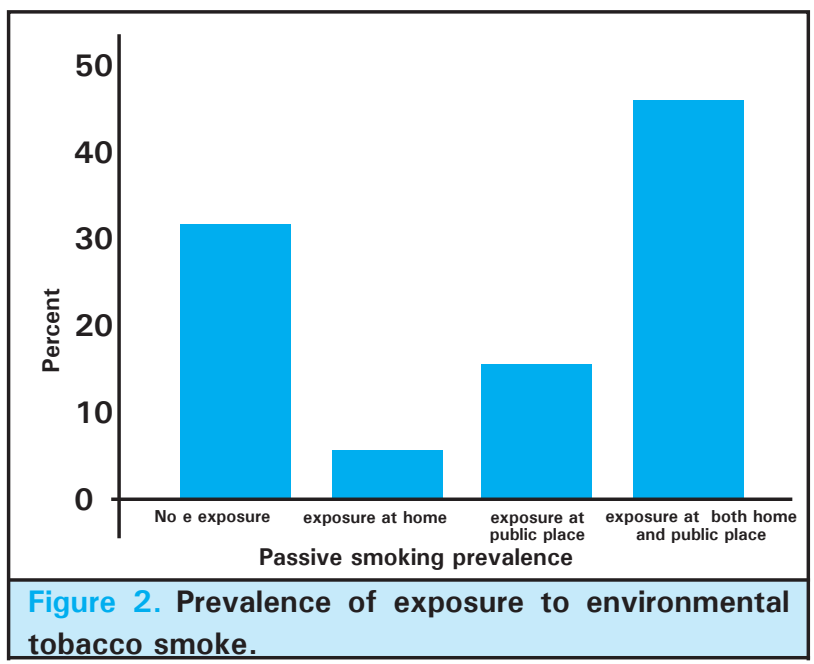

Compared to smokers, non-smokers had a view that health professionals needed to get specific training on cessation techniques i.e. 76 (96.2\%) in non-smokers vs. $27(79.4 \%)$ in smokers and that health professionals who smoke are less likely to advise patients to stop smoking i.e. 52 (65.8\%) in non-smokers vs. 14 (41.2\%) in smokers.

No major differences in opinion regarding view on health professionals serving as "role models" for their patients and the general population $67(84.8 \%)$ in non-smokers vs. $28(82.4 \%)$ in smokers as well as, regarding the view that health professionals should routinely give advice on quitting smoking 76 (96.2\%) in non-smokers vs. $34(100.0 \%)$ in smokers. And both groups believed that health professionals had a role in giving advice about smoking cessation to patients 76 (96.2\%) in nonsmokers vs. $33(97.1 \%)$ in smokers.

Most of the students, 105 (92.9\%) mentioned that the dangers of smoking were taught during the class. Similarly, $77(68.1 \%)$ of students were also taught about the reason for people smoking. Also the majority of students 106 (93.8\%) had learned about the importance of tobacco use history. About 87 (77\%) of students had learned the importance of providing educational materials regarding quitting smoking to support cessation of tobacco use for those who want to quit smoking. Only $32(28.3 \%)$ of the students actually received formal training regarding smoking cessation (Figure 3).

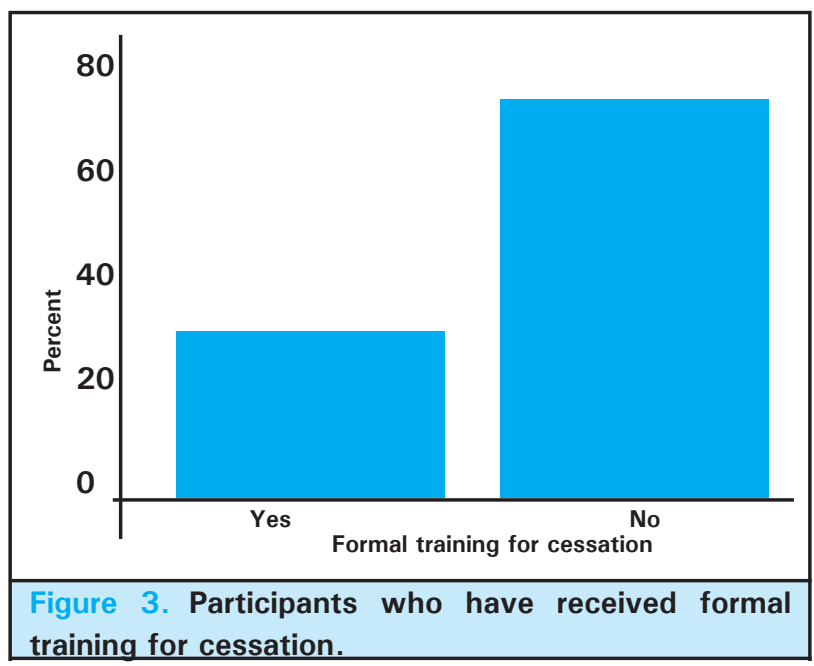

Most 100 (88.5\%) of the participants knew about nicotine replacement therapies, and 68 (60.2\%) were aware of the use of antidepressants for aiding cessation.

\section{DISCUSSION}

Tobacco use is currently the major risk factor for noncommunicable chronic illnesses, which is preventable. ${ }^{15}$ Health professionals play a pivotal role in the control of this existing problem. But, there are some crucial shortcomings; major being the health professionals themselves are prone to use tobacco.

In our study, the prevalence of smoking among thirdyear medical students was $30.1 \%$ which is lower than that of the general population (37\%) and higher than that of adolescents $(13.1 \%)$ at the national level. ${ }^{16}$ Using tobacco can not only risk the health of the medical students but will also undermine the credibility of the future health professional and his ability to deliver effective anti-tobacco counseling while managing future patients. ${ }^{17}$ Furthermore, cessation training if any provided to the health professionals proves to be inadequate, primarily in developing nations. ${ }^{18,19}$ This will most undoubtedly result in the inefficiency of health professionals in helping patients in the cessation of smoking.

The prevalence rate found in our study was similar to 
studies done in Europe by Torre, et al. which found the prevalence of $29.3 \%$ and by Turhan, et al. in Turkey with a prevalence of $28.5 \%$. But the prevalence in our study was found to be much higher than the study done by Sreeramareddy, et al. in India which found a prevalence of current smokers of only $13.1 \%$. This finding is not satisfactory as it questions the ability of health professionals who smoke to deliver consistent messages to the patients regarding cessation and smoking-related diseases, thus it would be better if they are provided with knowledge and specific skills required for counselling. ${ }^{20}$

Our study found that the prevalence was higher among males compared to that of females, $23.0 \%$ vs. $7.1 \%$ respectively. This finding was similar to the study conducted by Turhan, et al. and Sreeramareddy, et al. ${ }^{21,22}$ The increase in prevalence in females might be due to the aggressive marketing strategy of the tobacco industry for lighter cigarettes for the woman. ${ }^{22}$ In contrast, a study conducted by Kusma, et al. in Berlin found no such differences. ${ }^{23}$

The prevalence of ever smokers in this study was found to be $49.6 \%$, which is lower than the similar study done by Ferrante $M$, et al. which found ever smoker rate of much higher $74 \% .{ }^{20}$ Similarly, a study done by Cauchi, et al. in Malta found a prevalence of $65.9 \%{ }^{24}$ In contrast, the study was done by Sreeramareddy, et al. found the ever smoker prevalence of only $31.7 \% .^{25}$ Several factors such as tobacco control legislation, programs, and policies, tobacco production, tobacco export and import, taxation present on tobacco products, as well as socio-economic environment play an important role in the increase in the prevalence of current smokers and ever smokers.

Our study revealed that $23.9 \%$ of the students had tried cigarettes for the first time in the later adolescence years (20-24 years) which is in contrast to a similar study done by Torre, et al. in Europe which found that 34.4\% of students had tried their first cigarette in the early adolescence years (11-19 years). ${ }^{26,27}$ These findings could be because of poor tobacco control legislation concerning purchase by adolescents and sales.

In the study, $96.2 \%$ of the students opined that health professionals had a positive role in giving advice for the cessation of smoking. The finding is higher than that of similar studies done by Ferrante, et al. which found that only $65 \%$ of students believed that health professionals had a role in giving advice for cessation. This is a good finding, as if students give much importance to physician's advice for the cessation of smoking, they will most likely make an effort to provide smoking prevention counseling when they themselves become the practitioners. Non-smokers thought that it was necessary for health professionals to get specific training on cessation techniques $196.2 \%$ in nonsmokers vs. $79.4 \%$ in smokers), which is comparable to the findings from a study done by Ferrante $M$, et al. (96.6\% in non-smokers vs $90.7 \%$ in smokers). This shows regardless of the smoking status of an individual, most believe it is important to get specific techniques for cessation although it is slightly lower in smokers. ${ }^{20}$

In our study, only 32 (28.3\%) of the students actually received a formal training regarding smoking cessation this aligns with the survey done by Sreeramareddy $\mathrm{CT}$, et al. which deals with country wise aggregate data, where the reporting of formal training in smoking ranged from $9.2 \%$ to $36.9 \% .^{25}$ This shows overall low rates of actual inclusion of formal training regardless of the country of the medical school, even if the students themselves believe that there is a necessity of proper training of the cessation techniques.

Passive smoke exposure remains the main issue in countries like ours. This study shows only $31.9 \%$ had no exposure while $46.9 \%$ had exposure to tobacco smoke both at home and public, exposure at only home being $5.3 \%$ and exposure at only public places being $15.9 \%$, exposing them to more than 4000 chemicals identified in tobacco smoke, among which at least 250 known to be harmful and more than 50 of which are known to cause cancer. Although filters and fans are used, these toxins can remain in the room for weeks as discussed in WHO report on Global Tobacco epidemic 2009. ${ }^{28}$

This study is a cross-sectional study that has some inevitable limitations. It gives a snapshot result of prevalence only in the specific student group selected and cannot be used to generalize among the public. However, GHPSS is a well-established tool for data collection. A self-reported questionnaire format was used although the GHPSS mainly focuses on interviewbased data collection. Still, this creates a chance of social desirability bias and reporting bias. Participants were clearly informed about the anonymity and completely voluntary status of the study to minimize the biases.

\section{CONCLUSIONS}

The prevalence of smoking among the participants is relatively high than the standard national data. Medical students are future health professionals thus should get proper cessation advice and training in proper cessation counseling techniques for future smoker patients. An 
inclusive curriculum and proper practical sessions are a must to aid WHO tobacco control efforts. Academic, medical, and policymaking communities should come together to create a better environment for the present medical students, to aid the prevention of noncommunicable diseases.

\section{ACKNOWLEDGEMENTS}

Our sincere thanks to all the medical students who participated in the study to make this study possible.

Conflict of Interest: None.

\section{REFERENCES}

1. World Health Organization. WHO global report on mortality attributable to tobacco [Internet]. Geneva (Switzerland): World Health Organization; 2012 [cited 2020 Jan 31]. Available from: https://www.who.int/tobacco/ publications/surveillance/rep_mortality_attributable/en/. [Full Text]

2. American Cancer Society. Cancer Facts \& Figures 2019 [Internet]. Atlanta (US): American Cancer Society; 2019 [cited on 2020 Jan 31]. Available from: https://www.cancer. org/content/dam/cancer-org/research/cancer-factsand-statistics/annual-cancer-facts-and-figures / 2019/ cancer-facts-and-figures-2019.pdf. [Full Text]

3. $\mathrm{Ng} \mathrm{M}$, Freeman MK, Fleming TD, Robinson $\mathrm{M}$, Dwyer-Lindgren L, Thomson B, et al. Smoking prevalence and cigarette consumption in 187 countries, 1980-2012. JAMA. 2014 Jan 8;311(2):183-92. [PubMed | Full Text | DOI]

4. Guindon GE, Boisclair D. Economics of tobacco control paper. 6: past, current and future trends in tobacco use [Internet]. Washington (US); International Bank for Reconstruction and Development: 2003 Mar [cited 2020 Jan 31]. Available from: http:/ / siteresources.worldbank.org/HEALTHNUTRITIONANDPOPULA TION / Resources / 281627 1095698140167/Guindon-PastCurrent-whole.pdf. [Full Text]

5. Mackay J, Crofton J. Tobacco and the developing world. Br Med Bull. 1996 Jan 1;52(1):206-21. [ㄹuMed | Full Text | DOI]

6. Carr $\mathrm{AB}$, Ebbert JO. Interventions for tobacco cessation in the dental setting. Cochrane Database Syst Rev. 2006 Jan 25;(1):CD005084. [PubMed | Full Text | DOI]

7. Stead LF, Buitrago D, Preciado N, Sanchez G, Hartmann $\square$ Boyce J, Lancaster T. Physician advice for smoking cessation. Cochrane Database Syst Rev. 2013 May 31;(5):CD000165. [PubMed | Full Text | DOI]

8. World Health Organization. WHO Framework Convention on Tobacco Control [Internet]. Geneva (Switzerland): WHO Document Production Services; 2003 [updated 2004, 2005; cited 2020 Jan 31]. 42 p. Available from: https://www.who. int/fctc/text_download/en/. [Full Text]

9. Richmond R, Zwar N, Taylor R, Hunnisett J, Hyslop F. Teaching about tobacco in medical schools: a worldwide study. Drug and alcohol review. 2009 Sep;28(5):484-97. [PubMed $\mid$ Full Text $\mid \underline{\text { DOI] }}$

10. Smith DR, Leggat PA. An international review of tobacco smoking among dental students in 19 countries. Int Dent J. 2007 Dec;57(6):452-8. [랄ed | Full Text | DOI]
11. Smith DR, Leggat PA. An international review of tobacco smoking among medical students. J Postgrad Med. 2007 Jan 1;53(1):55. [ [PubMed | Full Text | DOI]

12. Gualano MR, Bontempi C, Saulle R, Ricciardi W, La Torre G. Validation of the global health professions students survey questionnaire in Italy. Italian Journal of Public Health. 2011;8(4):392-8. [Full Text | DOI]

13. World Health Organization, Regional Office for South-East Asia. The WHO FCTC indicators: global health professions student survey (medical), 2005-2009 [Internet]. New Delhi (India): World Health Organization Regional Office for South-East Asia; 2011 [cited 2020 May 23]. Available from: https://apps.who.int/iris/handle/10665/206002. [ [Full Text]

14. Sreeramareddy CT, Kishore PV, Paudel J, Menezes RG. Prevalence and correlates of tobacco use amongst junior collegiates in twin cities of western Nepal: a cross-sectional, questionnaire-based survey. BMC Public Health. 2008 Dec;8(1):97. [Full Text | DOI]

15. Warren CW, Sinha DN, Lee J, Lea V, Jones N, Asma S. Tobacco use, exposure to second hand smoke, and cessation counseling training of dental students around the world. J Dent Edu. 2011 Mar 1;75(3):385-405. [PubMed | DOI]

16. Ministry of Health and Population, Population Division. Nepal Demographic and Health Survey 2011 [Internet]. Kathmandu (Nepal): Ministry of Health and Population, New ERA, and ICF International, Calverton, Maryland; 2012 [cited 2020 Jan 31]. 421 p. Available from: https://dhsprogram. com/pubs/pdf/FR257/FR257\%5B13April2012\%5D.pdf. [Full Text]

17. Warren CW, Sinha DN, Lee J, Lea V, Jones NR. Tobacco use, exposure to secondhand smoke, and training on cessation counseling among nursing students: cross-country data from the Global Health Professions Student Survey (GHPSS), 2005-2009. Int J Environ Res Public Health. 2009 Oct;6(10):2534-49. [PubMed | Full Text | DOI]

18. Abdullah AS, Husten CG. Promotion of smoking cessation in developing countries: a framework for urgent public health interventions. Thorax. 2004 Jul 1;59(7):623-30. [Full Text | $\underline{\mathrm{DOI}}$

19. Muramoto ML, Lando H. Faculty development in tobacco cessation: training health professionals and promoting tobacco control in developing countries. Drug Alcohol Rev. 2009 Sep;28(5):498-506. [라Med | Full Text | DOI] 
20. Ferrante M, Saulle R, Ledda C, Pappalardo R, Fallico R, La Torre G, et al. Prevalence of smoking habits, attitudes, knowledge and beliefs among Health Professional School students: a cross-sectional study. Ann Ist Super Sanita. 2013;49:143-9. [라Med | Full Text | DOI]

21. Turhan E, Inandi T, Col M, Bugdayci R, Eker O, Ilhan M. Smoking cessation and attitudes, belief, observation, and education of medical students, in Turkey. J Nepal Med Assoc. 2016 Apr 1;54(202). [PubMed | DOI]

22. Sreeramareddy CT, Suri S, Menezes RG, Kumar HH, Rahman M, Islam MR, et al. Self-reported tobacco smoking practices among medical students and their perceptions towards training about tobacco smoking in medical curricula: a cross-sectional, questionnaire survey in Malaysia, India, Pakistan, Nepal, and Bangladesh. Subst Abuse Treat Prev Policy. 2010 Dec;5(1):29. [Full Text]

23. Kusma B, Quarcoo D, Vitzthum K, Welte T, Mache S, Meyer-Falcke A, et al. Berlin's medical students' smoking habits, knowledge about smoking and attitudes toward smoking cessation counseling. J Occup Med Toxico. 2010 Dec 1;5(1):9. [Full Text]
24. Cauchi D, Mamo J. Smoking health professional student: an attitudinal challenge for health promotion? Int J Environ Res Public Health. 2012 Jul;9(7):2550-61. [Full Text]

25. Sreeramareddy CT, Ramakrishnareddy N, Rahman M, Mir IA. Prevalence of tobacco use and perceptions of student health professionals about cessation training: results from Global Health Professions Students Survey. BMJ open. 2018 May 26;8(5):e017477. [ㅁubMed | Full Text | DOI]

26. Sawyer SM, Azzopardi PS, Wickremarathne D, Patton GC. The age of adolescence. The Lancet Child \& Adolescent Health. 2018 Mar 1;2(3):223-8. [Full Text]

27. La Torre G, Kirch W, Bes-Rastrollo M, Ramos RM, Czaplicki M, Gualano MR, et al. Tobacco use among medical students in Europe: results of a multicentre study using the Global Health Professions Student Survey. Public health. 2012 Feb 1;126(2):159-64. [Full Text]

28. World Health Organization. WHO report on the global tobacco epidemic, 2009: implementing smoke-free environments [Internet]. Geneva (Switzerland): World Health Organization; 2009 [cited 2020 Jan 31]. 136 p. Available from: https://www.who.int/tobacco/mpower/2009/gtcr download/en/. [Full Text] 